9. Johnson BW, Kosoy O, Hunsperger E, Beltran M, Delorey M, Guirakhoo F, et al. Evaluation of chimeric Japanese encephalitis and dengue viruses for use in diagnostic plaque reduction neutralization tests. Clin Vaccine Immunol. 2009;16:1052-9. http:/ / dx.doi.org/10.1128/CVI.00095-09

10. Inwani I, Osoro E, Mugo C, Hunsperger E, Omballa V, Wamalwa $\mathrm{D}$, et al. Zika infection among pregnant women in Mombasa, Coastal Kenya, 2017-2018: preliminary results of a cohort study. Poster presented at: American Society for Tropical Medicine and Hygiene 67th annual meeting; 2018 Oct 30; New Orleans, LA, USA.

Address for correspondence: Marc-Alain Widdowson, Institute of Tropical Medicine, Kronenburgstraat 43, 2000 Antwerp, Belgium; email: mawiddowson@itg.be; Elizabeth Hunsperger, Centers for Disease Control and Prevention, Unit 8900 Box 3600, DPO, AE 09831, USA; email: enh4@cdc.gov

\section{Mycobacterium bovis Pulmonary Tuberculosis after Ritual Sheep Sacrifice in Tunisia}

\author{
Jamal Saad, Sophie Baron, Jean-Christophe Lagier, \\ Michel Drancourt, Phillipe Gautret
}

Author affiliations: IHU Méditerranée Infection, Marseille, France (J. Saad); Aix-Marseille-Université, Marseille (J. Saad, S. Baron, J.-C. Lagier, M. Drancourt, P. Gautret)

DOI: https://doi.org/10.3201/eid2607.191597

A woman in France was diagnosed with pulmonary tuberculosis caused by Mycobacterium bovis after a ritual sheep sacrifice in her home country of Tunisia. This investigation sheds light on ritual sacrifice of sheep as a circumstance in which religious tradition and practices can expose millions of Muslims worldwide to this disease.

ycobacterium bovis is historically responsible for
zoonotic, deadly tuberculosis and has seem-
ingly reemerged in countries where it had previ-
ously vanished following eradication programs in
cattle and the pasteurization of dairy products (1-3).
In most cases, $M$. bovis tuberculosis results from con-
suming unpasteurized milk; extrapulmonary disease is thus the most frequent clinical manifestation (4-6). Also, $M$. bovis could be an airborne zoonotic pathogen causing pulmonary tuberculosis (7). In western Europe countries, most of $M$. bovis human tuberculosis cases are seen in migrants and are associated with travel to the country of origin $(4,5,8,9)$. M. bovis tuberculosis is traced to animal sources, yet reporting of clinical signs and symptoms is often delayed (3). The observation of a woman affected by $M$. bovis tuberculosis who participated in a precisely dated religious practice involving sheep slaughtering provided an opportunity to shed light on these medical aspects.

A 43-year-old unemployed woman born in Tunisia emigrated to France in 2000, married, and had 2 children. The patient had no underlying chronic condition, no medical history, no treatment, no history of smoking, and no toxic habits. She had received the bacillus Calmette-Guérin vaccine during childhood. Her last trip to Tunis and surrounding areas was during July 10-August 28, 2018. The patient denied any contacts with ill persons during her stay. She participated in the Aid-el-Kebir (the Great Festival) Muslim festivities on August 22-23, 2018. After the ritual, her husband slaughtered a veterinary-uncontrolled sheep outside the house by cutting through its neck in an open place and then insufflating air beneath the skin of the dead animal using bellows before butchering the viscera, including lungs, heart, liver, and kidneys, which were put into a container while the digestive tract was put separately into another container. His wife then washed the lungs and the other viscera for $\approx 2$ hours in a confined kitchen, cooked them, and consumed them with her family; she did not experience any injury while butchering the animal.

After her return to France, the patient was apyretic with productive cough, fatigue, and anorexia, which started exactly 22 days after the Aid-el-Kebir festivities ended. The patient attributed symptoms to allergy and did not consult with a healthcare professional. In December 2018, her respiratory tract symptoms persisted; she also developed fatigue, fever, and night sweats and consulted a general practitioner. In January 2019, a computerized tomodensitometry scan confirmed an abscess in the inferior lobe of the patient's left lung with thick walls and an infiltrate in the lower lobe of the right lung. The patient reported fever, cough, expectoration, and anorexia, and lost 5 $\mathrm{kg}$ within 1 month (body mass index 15); we found crackles in both the left inferior and right superior lobes. She did not report hemoptysis, and her physical examination was otherwise unremarkable. Blood examination showed an iron deficiency in microcytic anemia, and her leukocyte count was normal. 


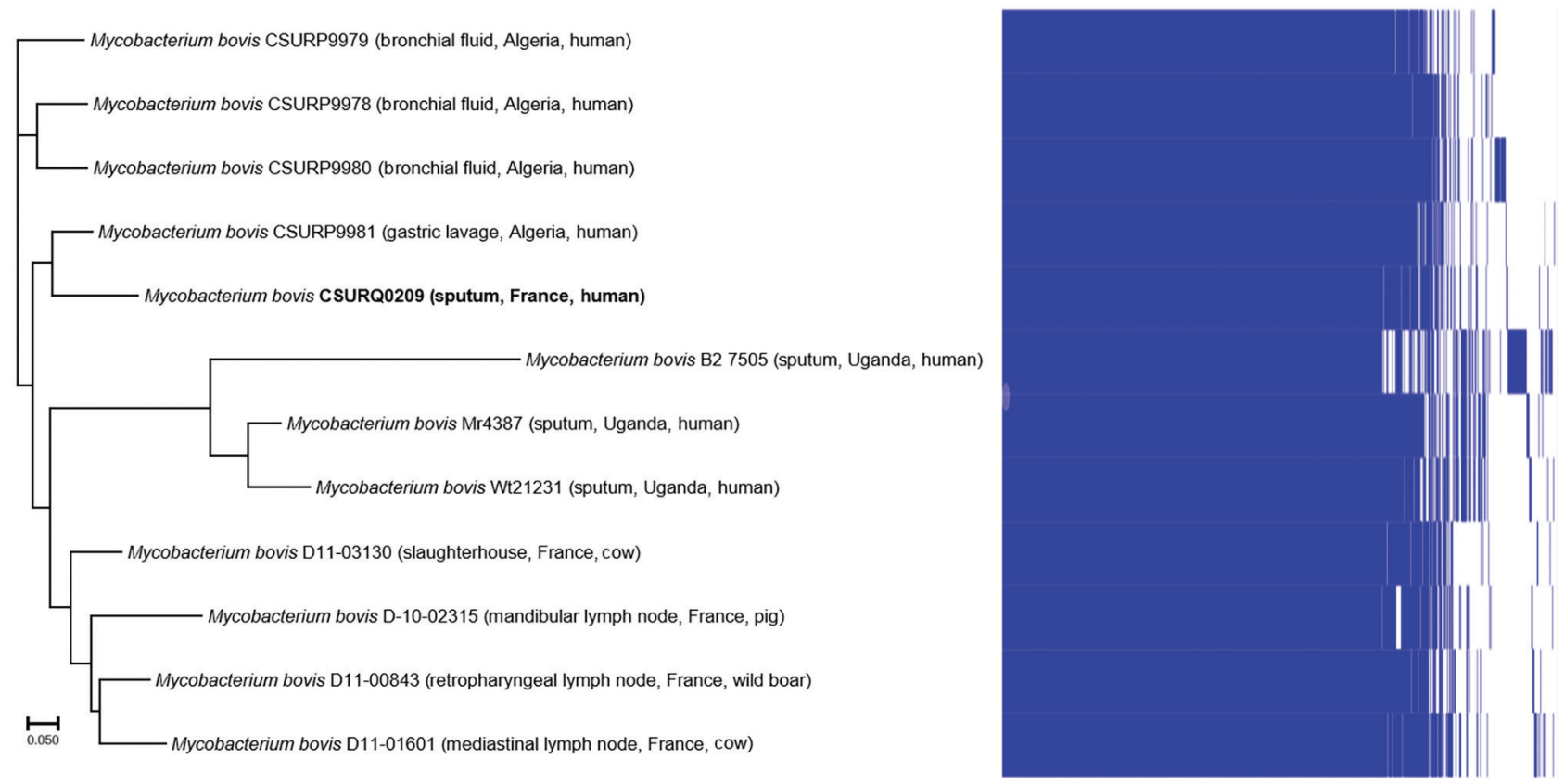

Figure. Pangenome tree of Mycobacterium bovis from a patient in France (bold; GenBank accession no. CSURQ0209) with 11 reference Mycobacterium bovis strains isolated from different regions and hosts. The patient had visited her home country, Tunisia, where she participated in the ritual slaughter of a sheep. Scale bar represents $5 \%$ sequence divergence.

We performed a GenExpert assay (Cepheid, https://www.cepheid.com) and detected M. tuberculosis complex DNA in 1 sputum sample; we cultured the M. tuberculosis complex CSURQ0209 strain. None of the patient's other family members had any pulmonary symptoms at any time, and their chest radiographs results were normal. Before the precise M. bovis identification was known, we administered to the patient a daily oral regimen of rifampin (480 $\mathrm{mg})$, isoniazid (200 mg), pyrazinamide $(1,200 \mathrm{mg})$, and ethambutol $(1,000 \mathrm{mg})$ for 2 months, followed by rifampin $(600 \mathrm{mg} / \mathrm{d})$ and isoniazid $(300 \mathrm{mg} / \mathrm{d})$ for 4 additional months, with favorable clinical and radiological outcomes and excellent tolerance. Wholegenome sequence analysis of strain CSURQ0209 (GenBank accession no. PRJEB39431) showed that it grouped more proximately with $1 \mathrm{M}$. bovis strain isolated from a patient from Algeria (Figure).

In this case, slaughtering a sheep during the annual ritual Aid-el-Kebir festivities was a probable source of infection, although no animal remains were available to confirm this hypothesis. Genome sequence analysis confirmed the identification of $M$. bovis, clustering with isolates from Algeria, in the absence of any other sequence from Tunisia. These results reinforced that this patient had been infected in her native country. During previous years, the festivities took place at the time the family was in France, and no animal sacrifice was performed on these occasions.
Transmission of $M$. bovis may occur during slaughtering through the inhalation of aerosols exhaled by infected animals (9). In this case, the patient was most likely infected by aerosols after prolonged manipulation of the crude viscera. This case potentially concerns millions of Muslim persons worldwide. Our findings indicate that, in countries where ritual animal sacrifices take place, health authorities may want to work with religious authorities to advocate veterinary inspection of slaughtered animals to discard viscera from animals with suspected tuberculosis, in phase with the current World Health Organization roadmap against zoonotic tuberculosis (10).

\section{About the Author}

Mr. Saad is a PhD student at Aix-Marseille Université, Marseille, France, with interest in developing appropriate methods for the real-time genomics diagnosis of mycobacterial infections, including tuberculosis.

\section{References}

1. Good M, Bakker D, Duignan A, Collins DM. The history of in vivo tuberculin testing in bovines: tuberculosis, a "One Health" issue. Front Vet Sci. 2018;5:59. https://doi.org/10.3389/fvets.2018.00059

2. Cousins DV. Mycobacterium bovis infection and control in domestic livestock. Rev Sci Tech. 2001;20:71-85. https://doi.org/10.20506/rst.20.1.1263 
3. Good M, Duignan A. Perspectives on the history of bovine $\mathrm{TB}$ and the role of tuberculin in bovine TB eradication. Vet Med Int. 2011;2011:410470. https://doi.org/10.4061/ 2011/410470

4. Majoor CJ, Magis-Escurra C, van Ingen J, Boeree MJ, van Soolingen D. Epidemiology of Mycobacterium bovis disease in humans, the Netherlands, 1993-2007.

Emerg Infect Dis. 2011;17:457-63. https:/ / doi.org/10.3201/ eid1703.101111

5. Scott C, Cavanaugh JS, Pratt R, Silk BJ, LoBue P, Moonan PK. Human tuberculosis caused by Mycobacterium bovis in the United States, 2006-2013. Clin Infect Dis. 2016;63:594-601. https://doi.org/10.1093/cid/ciw371

6. Torres-Gonzalez P, Cervera-Hernandez ME, Martinez-Gamboa A, Garcia-Garcia L, Cruz-Hervert LP, Bobadilla-Del Valle M, et al. Human tuberculosis caused by Mycobacterium bovis: a retrospective comparison with Mycobacterium tuberculosis in a Mexican tertiary care centre, 2000-2015. BMC Infect Dis. 2016;16:657. https:/ / doi.org/ 10.1186/s12879-016-2001-5

7. Vayr F, Martin-Blondel G, Savall F, Soulat JM, Deffontaines G, Herin F. Occupational exposure to human Mycobacterium bovis infection: a systematic review. PLoS Negl Trop Dis. 2018;12:e0006208. https:/ / doi.org/ 10.1371/journal.pntd.0006208

8. Nebreda-Mayoral T, Brezmes-Valdivieso MF, Gutiérrez-Zufiaurre N, García-de Cruz S, LabayruEcheverría C, López-Medrano R, et al. Human Mycobacterium bovis infection in Castile and León (Spain), 2006-2015 [in Spanish]. Enferm Infecc Microbiol Clin. 2019;37:19-24. https://doi.org/10.1016/j.eimc.2017.11.018

9. Lepesqueux G, Mailles A, Aubry A, Veziris N, Jaffré J, Jarlier V, et al. Epidémiologie des cas de tuberculose à Mycobacterium bovis diagnostiqués en France. Med Mal Infect. 2018;48:S115-6. https:/ / doi.org/10.1016/ j.medmal.2018.04.291

10. World Health Organization. Roadmap for zoonotic tuberculosis. 2017 [cited 2019 Nov 29]. https:/ / www.who. int/tb/publications/2017/Roadmap_for_zoonotic_ tuberculosis_med_red.pdf

Address for correspondence: Michel Drancourt, Aix-Marseille Université IHU Méditerranée Infection, Unité de Recherche sur les Maladies Infectieuses et Tropicales Emergentes, UMR CNRS 6236 IRD 3R198, IFR 4827 Bd., Jean Moulin, Marseille 13385 CEDEX 05, France; email: michel.drancourt@univ-amu.fr

\section{Urogenital Schistosomiasis in Fisherman, Nepal, 2019}

\author{
Ranjit Sah, Jürg Utzinger, Andreas Neumayr \\ Author affiliations: Tribhuvan University Teaching Hospital, \\ Kathmandu, Nepal (R. Sah); Swiss Tropical and Public Health \\ Institute, Basel, Switzerland (J. Utzinger, A. Neumayr); University \\ of Basel, Basel (J. Utzinger, A. Neumayr)
}

DOI: https://doi.org/10.3201/eid2607.191828

We report a case of urogenital schistosomiasis in a 34-year-old male patient in Nepal and summarize additional case reports. These cases provide putative evidence for the potential existence of human-pathogenic (most likely zoonotic) schistosome species on the Indian subcontinent.

W e report the case of a 34-year-old male patient from Siraha District, Nepal, in the outer Terai Region bordering India. The patient was referred to us in October 2019 by his regional hospital because of a diagnosed microhematuria and reported intermittently observed episodes of macrohematuria. The patient reported no relevant medical history and had never traveled abroad other than to visit neighboring districts in Nepal and across the border to India. He earned his living as a fisherman.

Results of the physical examination were unremarkable. Laboratory test results showed a white cell count within reference ranges with mild eosinophilia $(14 \% ; 728$ cells $/ \mu \mathrm{L})$ and unremarkable results for renal and liver function tests. Urine analysis confirmed microhematuria, and microscopic examination of the urine sediment showed very few but typical trematode eggs, resembling those of Schistosoma haematobi$u m$, the causative agent of urogenital schistosomiasis (1) (Figure, panel A). An abdominal ultrasound examination revealed diffuse bladder wall thickening, which was confirmed by computed tomography (Figure, panel B).

After praziquantel treatment $(40 \mathrm{mg} / \mathrm{kg}$ for $3 \mathrm{~d})$, hematuria resolved, and no more eggs were detectable at follow-up 2 weeks later.

Although several zoonotic schistosome species have been reported from the Indian subcontinent, human-pathogenic schistosome species are considered absent from the region (2) because none of the known intermediate host snails involved in the lifecycle of human-pathogenic schistosome species are present. Nevertheless, some reports of parasitologic confirmed autochthonously acquired infections 